\title{
Editorial \\ Bienvenidos a la Revista 2017
}

\author{
"Todo hombre por naturaleza \\ tiene el deseo de saber"
}

Aristóteles

"La verdadera manifestación de la inteligencia no es el conocimiento sino la imaginación"

Albert Einstein

$\mathrm{H}$ onrado pero a la vez con humildad y un poco de susto!!! recibo la designación de editor de la revista chilena de anestesia. Tarea dura que presencié de primera mano dado que trabajo con un ex editor; Ricardo Bustamante y fui testigo de su ardua y fructífera labor. A él le correspondió lidiar con una revista de papel, en la cual era más complicado realizar correcciones y que requería entregar a la imprenta el total de manuscritos que iban a ser publicados. Por esto debemos estar agradecidos también de Sergio Cerda, mi antecesor, quien transformó la revista en una digital, facilitando la tarea de los editores posteriores.

Es verdad que al no estar indexada, hay poco interés por parte de los anestesiólogos chilenos de publicar en la revista nacional pero también es cierto que existe en nuestro medio un importante contingente de colegas que manejan un acervo de conocimiento que sería importante que fuera compartido con el resto de los anestesiólogos del país, de manera que si bien la gnosis actual se genera en los artículos originales, mientras estos llegan podemos empaparnos de la sapiencia de aquellos entre nuestros pares que puedan ilustrarnos acerca del uso de la ecocardiografía intraoperatoria, bioética, anestesia regional, anestesia intravenosa y tantos otros temas en los cuales existen reconocidos expertos nacionales.

Otra de mis metas será acercar a los lectores de la revista a la odiada pero necesaria Medicina Basada en la Evidencia, que ES la manera universal de construir conocimiento científico y es por supuesto el mecanismo en que se sustenta un buen artículo científico.

Todo lo anterior apuntando al objetivo cardinal cual es incorporar la revista a SciELO (scientifica electronic library online) y Pubmed, esto depende además de la periodicidad; debemos publicar al menos 3 números anuales que contengan una alta proporción de artículos originales si queremos ser parte de la redes universales de conocimiento médico.

Mi impresión es que debemos buscar esos artículos de investigación originales en los centros formadores que no son los tradicionales, aquellos que fueron denominados (con ánimo más bien simpático que ofensivo) "vulcanización de barrio como la mejor del centro". Es allí donde existe un semillero de anestesiólogos de donde se debe nutrir esta revista.

Yendo más a lo tangible, aspiro a incorporar nuevas secciones fijas que me parece deben existir en una revista de anestesia del siglo XXI: Ultrasonografía, Bioética, Educación, Economía y Gestión en anestesiología y por supuesto un rincón de los becados donde sean los más jóvenes los que nos enseñen a los más viejos. Pretendo también desempolvar una sección que me parece alguna vez existió, el "como lo hago yo", la opinión del experto porque las habilidades técnicas siempre se aprenderán observando y siguiendo los consejos de los maestros.

EL comité científico de la Sociedad Chilena de Anestesia desea además ofrecer asesoría a todo aquel que quiera publicar y precise de ayuda ya sea para realizar un análisis estadístico, redactar un resumen en inglés o resolver dudas acerca del diseño de un artículo. Esto con el fin altruista de incentivar la investigación pero al mismo tiempo con el objetivo un poco más egoísta de conseguir esos ansiados y escurridizos artículos originales que tanto necesitamos.

Y finalmente sólo me resta agradecer (y utilizar!) la colaboración voluntariamente ofrecida por muchos colegas y por un comité científico integrado por gente joven y entusiasta, con los que espero trabajar codo a codo.

Que la fuerza esté con nosotros.....!!!

Dagoberto Ojeda Dinamarca

Editor

Anestesiólogo Clínica Dávila

Magister Bioestadística Universidad de Chile 